\title{
Origin, Prediction and Prevention of Ischemic Heart Disease *
}

\author{
W. RAAB \\ The Professor Emeritus of Experimental Medicine University of Vermont, Burlington, Vermont U.S.A.
}

$\mathrm{T}$ HE TERM "coronary" heart disease is often arbitrarily used for the clinical designation of cardiac manifestations whose predominantly coronary vascular origin is uncertain and not always confirmed at autopsy. The development of multiple necrotic foci and of fibrotic scars in the subendocardium and sudden death or ultimate congestive heart failure can occur in the presence of only relatively insignificant coronary atherosclerosis or occasionally even in its complete absence ${ }^{1)}$.

Coronary atherosclerosis remains a causal factor of outstanding, though not unconditional importance in the above-named derangements, but the necessity to consider its coincidence with other functional and metabolic pathogenic influences is being increasingly recognized ${ }^{2) 37}$.

In order to avoid the traditional one-sided overemphasis on the purely vascular aspects of these cardiac syndromes in which a local oxygen deficiency in certain areas of the myocardium is involved, the somewhat misleading term "coronary" heart disease will be replaced in the following article by the now widely preferred term "ischemic" heart disease.

In Japan, the incidence of ischemic heart disease is much lower than in the Western countries, notably the United States of America, as pointed out by A. SEKI ${ }^{4}$, J. Gore, T. NAKAShima and P.D. White ${ }^{5)}$, N. Krmura ${ }^{6)}, \mathrm{K}$. TAMARI $^{7)}$, and others. Nevertheless, it poses a growing problem also in this country according to S. OKInAKA et $\mathrm{al}^{8}$.) and N. KIMURA ${ }^{6}$.

The low fat content of the average Japanese diet probably contributes in part to the relative infrequency of clinically diagnosed ischemic heart disease here, compared with the United States and Western Europe. ${ }^{9)}$ However, severe coronary atherosclerosis, found at autopsies in Japan in a frequency of about $1 / 10$ of that in the United States, is still relatively common, compared with the incidence of myocardial infarctions which occur in much smaller numbers $^{6)}$. Thus, certain discrepancies between autoptic findings on the coronary arteries and degenerative lesions of the myocardium exist in both countries, but in reversed proportions.

In America, thrombotic occlusion and coronary stenosis of a major degree are absent in 27 to 50 per cent of hearts with disseminated subendocardial necroses and non-penetrating infarcts of the left ventricular wall ${ }^{10) 11}$. The significance of these incompatibilities with the customary purely vascular interpretation of the origin of ischemic heart disease is still being disregarded by many Western pathologists and clinicians, but more adequately appreciated by German and Soviet authors ${ }^{2) 312 \text { ). }}$

In the following, the long neglected but fundamentally important involvement of autonomic nervous and hormonal factors in myocardial metabolic vulnerability will be discussed.

\section{Pathophysiology.}

It is generally agreed that the health of the heart muscle depends primarily on a sufficient availability of oxygen to the individual myocardial cell. The latter's oxygen economy is determined by the crucial ratio "Vascular oxygen supply: Myocardial oxygen consumption". Normally, this ratio is 1.0 or greater. When myocardial oxygen consumption rises, as it always does under increased activity of the catecholamine-liberating sympathetic and adreno-medullary system, the ratio is ordinari-

(Received for Publication, November, 19. 1964)

* This article is based on lectures given at the Tokyo District Circulation Society (October 7, 1964), and the Universities of Kurume (October 16, 1964) and Kobe (October 20, 1964). 


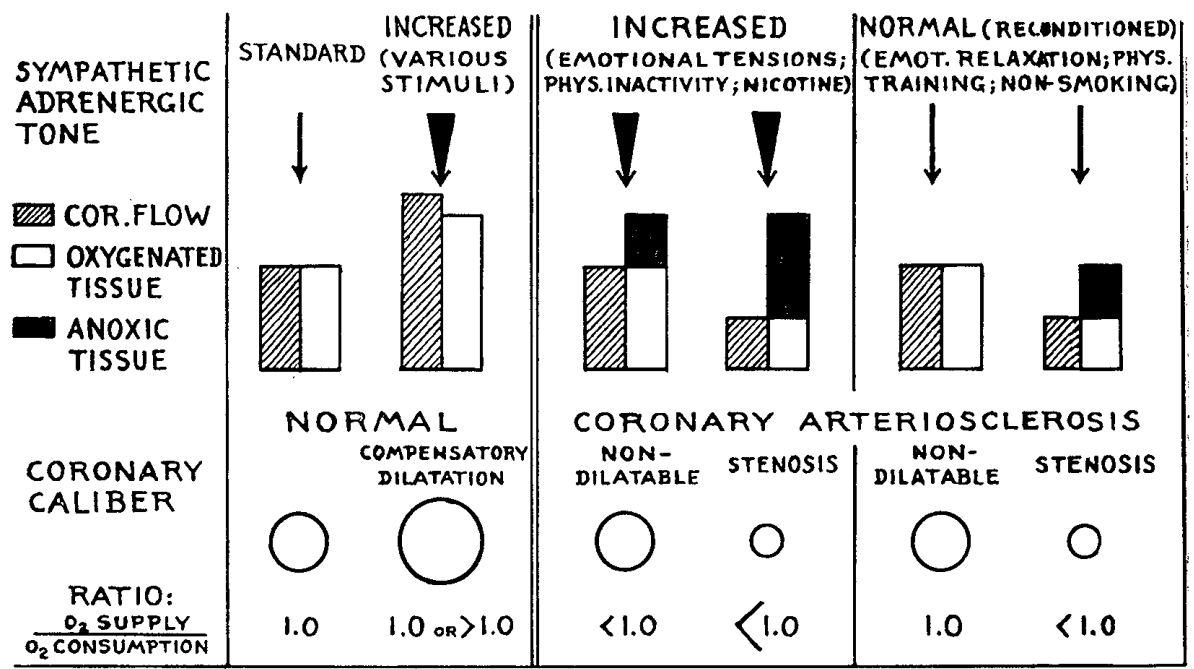

COORDINATED PRINCIPLES OF MYOCARDIALISCHEMIA AND OF ITS PREVENTION OR MITIGATION TROUGH NEURO-METABOLIC FUNCTIONAL RECONDITIONING

Fig. 1.

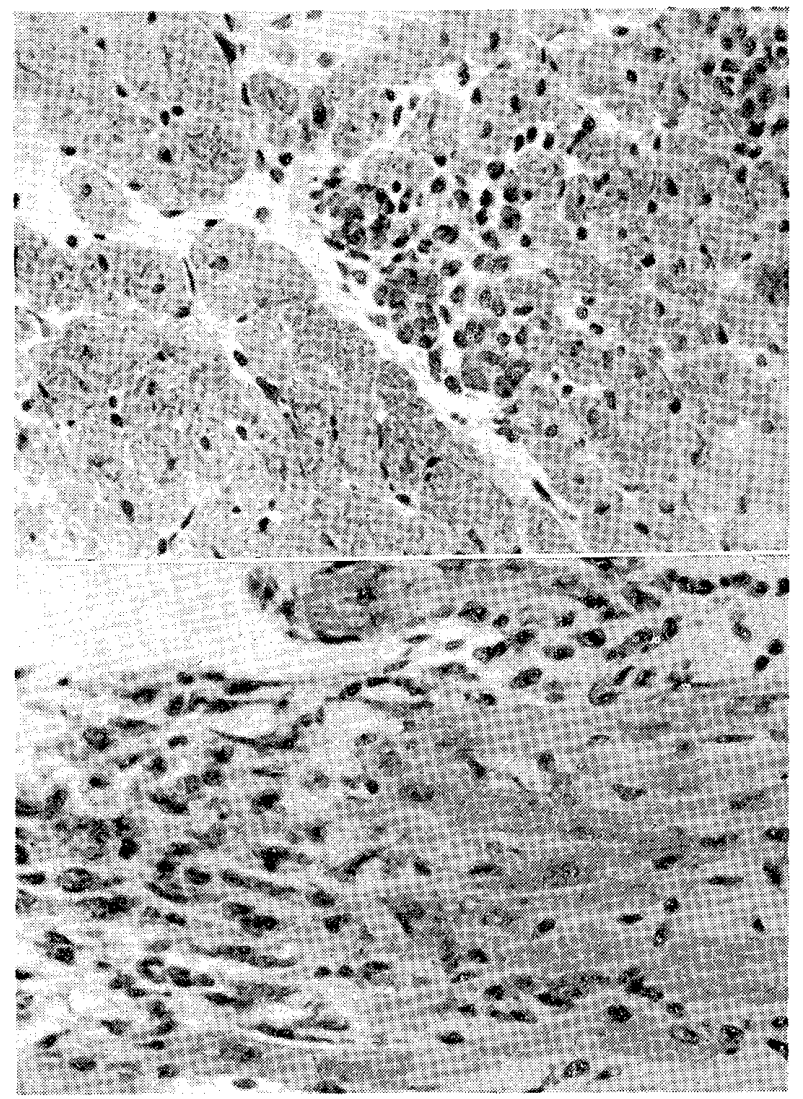

MYOCARDIAL NECROSES IN WILD RATS PRODUCED BY ANXIETY

(TAPE RECORDING OF CAT-RAT FIGHT)

(W. Raab et al. Proc. Soc. Exp. Biol. \& Med. 1964)

Fig. 2.

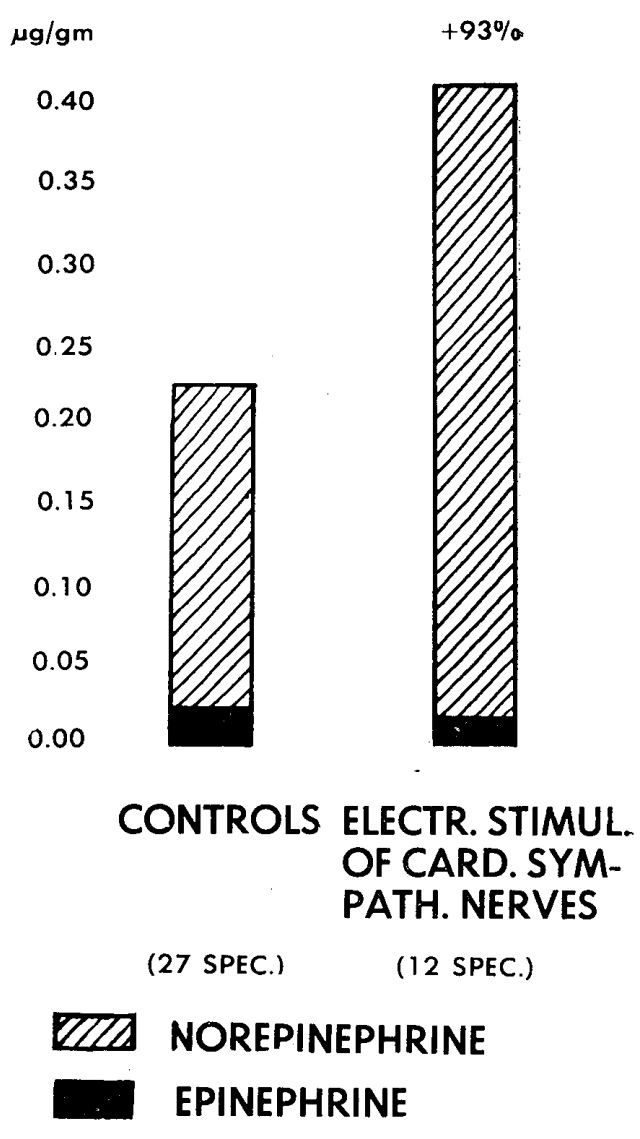

(W. Raab \& W. Gigee, Circul. Res. 3:553, 1955)

Fig. 3. ly maintained by the automatic compensatory dilatation of the coronary arteries. Major de- grees of adrenergic action, such as injection of large doses of catecholamines, pheochromocy- 


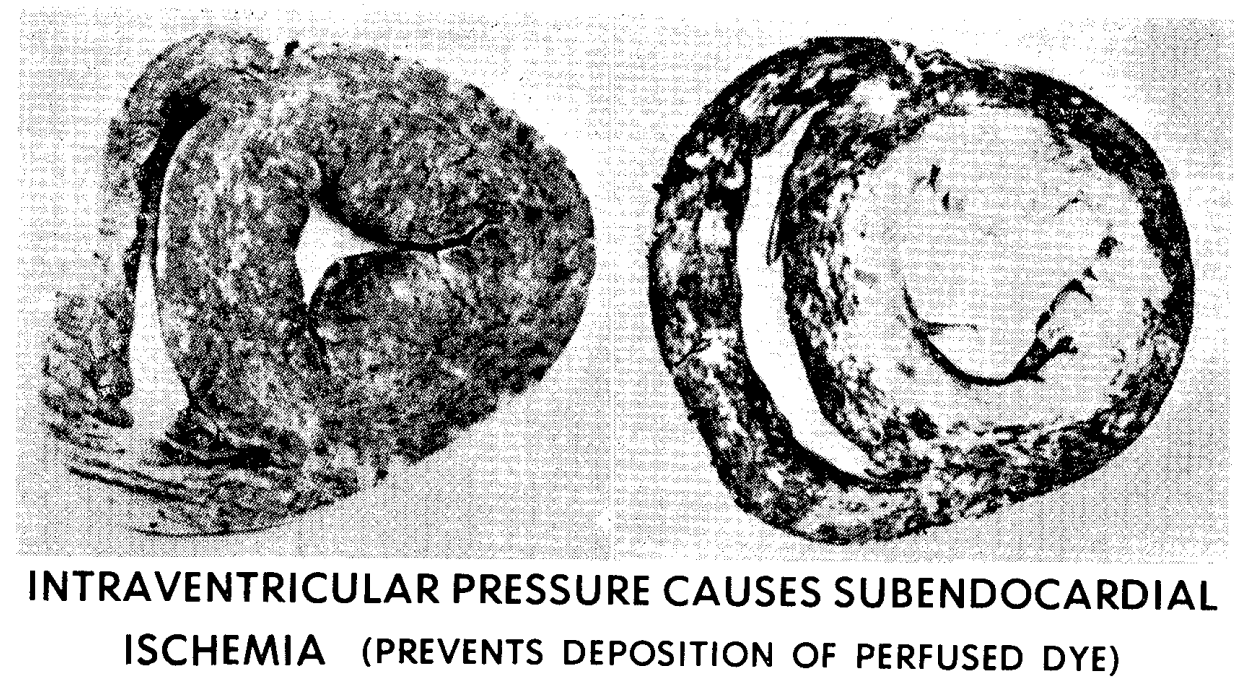

(E. Schütz, Verhandlgn. d. dtsch. Ges. f. Kreislaufforschg. 12:15, 1939)

Fig. 4.

toma-induced massive catecholamine discharges, and excessive catecholamine-liberating emotional stresses can surpass the compensatory capacity of the normal "coronary reserve" so that the ratio will fall below 1.0 and hypoxic myocardial lesions will develop. Under certain circumstances, the well-known myocardial oxygen consumption-exaggerating action of the adrenosympathogenic catecholamines, epinephrine and norepinephrine, is one of the most important primary or contributory factors in cardiac pathophysiology ${ }^{1) 13)}$ (Fig. 1).

The experimental production of subendocardial necroses by administration of epinphrine or norepinephrine has been observed by many authors (literature see 13, 14). Identical lesions and corresponding electrocardiographic manifestations in animals with normal coronary vessels have been provoked by lesions and stimulation of the brain ${ }^{15) 16}$, by emotional stresses, such as frustration and anxiety in baboons ${ }^{17)}{ }^{18)}$ and rats, ${ }^{19)}$ (Fig. 2) and by the administration of ganglionic-stimulating, catecholamine-liberating nicotine ${ }^{20)}$. Under such conditions, the myocardial catecholamine concentration was found increased ${ }^{16)}$ in analogy to the effect of electrical stimulation of the cardiac sympathetic nerves ${ }^{21)}$. (Fig. 3) Antiadrenergic drugs $^{22)}$ and hypothalamic inhibition ${ }^{22) 23)}$ prevent the development of stress-induced cardiac lesions. Electrocardiographic abnormalities were observed by Y. NAKABAYASHI ${ }^{24)}$, Y. $\mathrm{UEBA}^{25)}$, MeLville ${ }^{15)}$ and others after cerebral stimulations, lesions and hemorrhages. Y. $\mathrm{UEBA}^{25)}$ found the urinary excretion of catecholamines markedly augmented for several days after such events.

How can the origin of neurogenic multifocal necroses and their peculiar spotty distribution in the subendocardium be explained?

The subendocardial layers of the left ventricle are at a hemodynamic disadvantage. They have a comparatively poor arterial vascular supply ${ }^{26)}$, and their vascular network is exposed to ischemia-producing compression when the intraventricular pressure rises ${ }^{27-29)}$ (Fig. 4), as it is the case especially under the action of norepinephrine.

The relative length of the ventricular diastole, which provides optimal conditions for coronary blood flow is shortened and the relative length of the coronary flow-restricting systole is prolonged under the influence of the sympathogenic catecholamines ${ }^{30)}$.

Finally, even a considerable coronary vascular dilatation may not suffice to maintain an adequate $\mathrm{O}_{2}$ supply for unfavorably located cells. These factors combined are believed to account for the seemingly paradoxical observation that, under catecholamine action, despite an abundant oxygen supply to the bulk of the heart muscle ${ }^{31)}$ and augmentation of the oxygen 


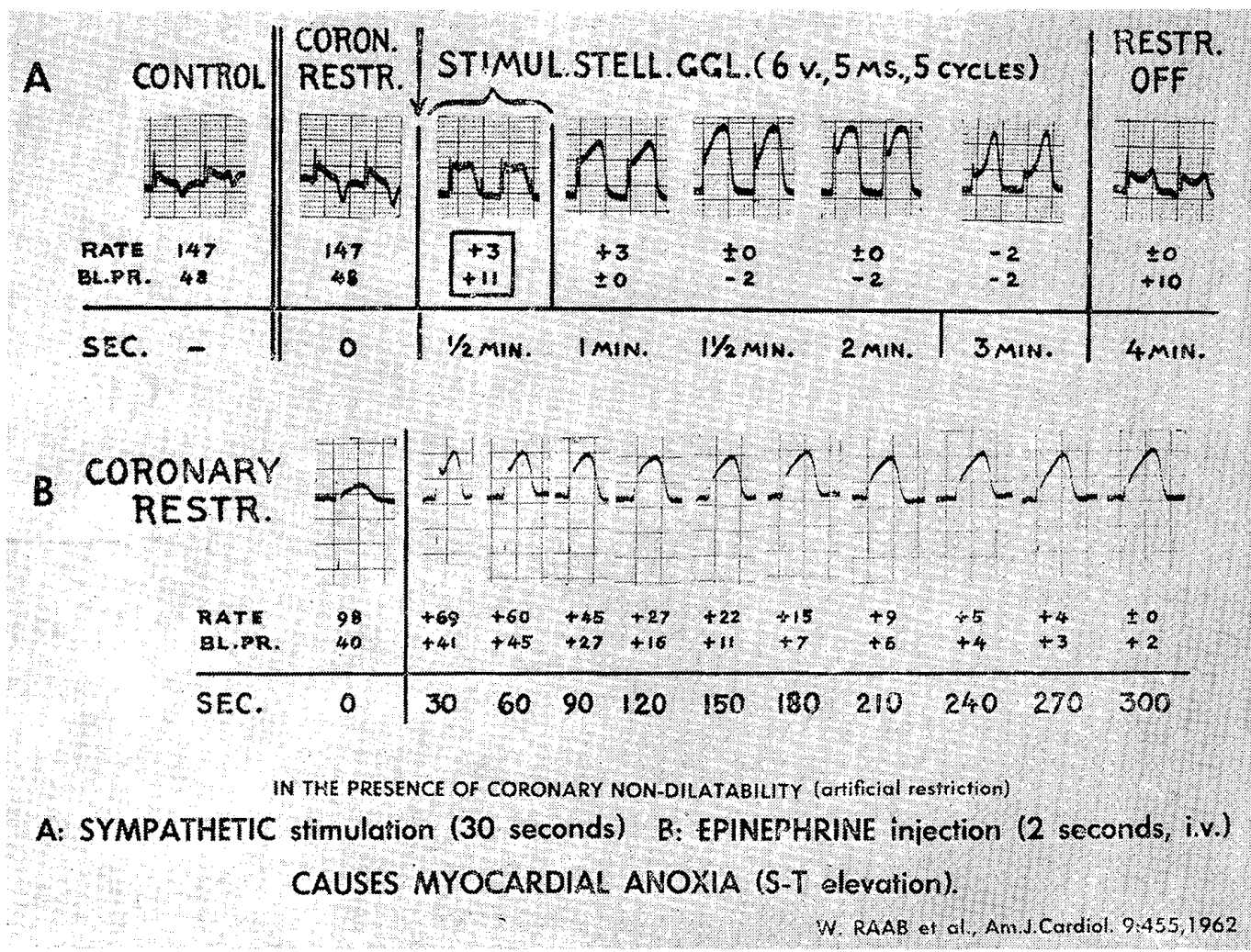

Fig. 5.

saturation in the coronary sinus blood ${ }^{32)}$, the latter contains also excess amounts of lactic $\operatorname{acid}^{32)}$, probably deriving from "handicapped" anoxic areas in the subendocardium.

Histochemical studies have shown that the injection of epinephrine is followed within minutes by a drastic dislocation of potassium from focal areas which are totally depleted, into adjacent cells where it accumulates in excess. These changes are paralleled by a similar dislocation of glycogen and of phosphorylase activity. They appear hours before conventional staining techniques reveal any structural alterations ${ }^{33)}$. Qualitatively, they resemble the changes produced by coronary ligation and anoxia. ShImamoto ${ }^{34)}$ has recently found by electron microscopy the appearance of spotty edematous changes in the heart muscle of rats, 30 minutes after the injection of epinephrine. They are also qualitatively similar to those elicited by general hypoxia ${ }^{35-37)}$.

Since H. SELYE ${ }^{38)}$ and others have shown that the cardiotoxic effect of the catecholamines is greatly augmented by adrenal corticoids, it appears reasonable to assume that the simul- taneous rise of both catecholamines and corticoids in the blood, for example under emotional stress $^{39740)}$, constitutes an additional hazard to the structure of the heart muscle.

Obviously, an impairment of the compensatory coronary dilatability is bound to cause a critical degree of local hypoxia when myocardial oxygen consumption rises. (Fig. 1) The ratio "Vascular oxygen supply: Myocardial oxygen consumption" will rapidly fall below 1.0 in the affected areas, whenever oxygenwasting sympathetic and adrenomedullary catecholamines are liberated. We have demonstrated this by restricting one major coronary artery with a snugly fitting ligature to the point where changes in the left ventricular surface electrocardiogram became barely noticeable. According to E. Kimura ${ }^{41)}$, this corresponds to a reduction of the coronary flow of approximately 35 per cent. Under these conditions, the electrocardiogram showed marked anoxic elevations of ST when epinephrine or norepinephrine was injected, or when the stellate ganglion was stimulated, (Fig. 5) or when acute reflex activation of the sympathetic sys- 
tem was provoked by electrical stimulation of the leg muscles. ${ }^{42)}$ The same phenomenon was elicited by the injection of nicotine in animals with restricted coronary arteries ${ }^{43}$. Discharges of catecholamines into the blood under the influence of nicotine have been regularly observed by Y. SATAKE ${ }^{44)}$ and others.

In patients with coronary atherosclerosis the electrocardiographic manifestations of myocardial anoxia are likewise greatly exaggerated under a variety of physical and emotional stimulations of the sympathetic system, including nicotine ${ }^{30}$.

The characteristic increase of catecholamine concentrations in the blood and urine of patients with congestive heart failure, as described during exercise and even at rest, by T. TomoMATSU $^{45)}$ and CHIDSEY ${ }^{46)}$, may possibly be regarded as a phenomenon induced by the stress of general tissue hypoxia in such cases.

Altogether it can be said that an exaggerated activity of the catecholamine-liberating sympathetic nervous system must be considered as an important, potentially contributing pathogenic element in the origin of and clinical course of ischemic heart disease, particularly if it coincides with a sclerotic impairment of compensatory coronary dilatability (Fig. 1).

\section{Pathogenic Epidemiology}

Extensive epidemiologic studies have provided a large body of evidence to demonstrate that, apart of excessive dietary fat consumption, three outstanding characteristic peculiarities of living habits in the industrialized prosperous countries of North America and Western Europe are prominently involved in their enormous mortality from premature ischemic heart disease and myocardial infarction.

These three factors are: (1) the emotional tensions, anxieties and frustrations, the sensory annoyances (e.g., industrial and traffic noises), and the personality types prevalent in a materialistic, acquisitive, competitive society ; (2) the nearly universal lack of physical exercise, and (3) excessive tobacco smoking.

All of these conditions are associated with an exaggerated activity of the sympathoadreno-medullary system and with a resulting augmentation of catecholamine action on the heart muscle.

ad 1: Emotional Stress-An augmented urinary excretion of catecholamines occurs under tension-producing working conditions and under various emotional and sensory stresses ${ }^{47}$. It has been observed also during daily activities in ambitious, high-strung perfectionist persons 48). The incidence of ischemic heart disease in this large category of individuals was found markedly increased ${ }^{49}$. In various professional groups, those subjected to greater emotional tensions and restlessness had a cardiac morbidity 2 to 3 times higher than that of their less harassed colleagues (for example physicians in general practice versus dermatologists or pathologist $\left.{ }^{50)}\right)$.

By contrast, an unusually low incidence of ischemic heart disease was observed in populations with an entirely different, emotionally uncomplicated, non-competitive, and placid mentality ${ }^{51) 52)}$, associated with low catecholamine excretion in the urine ${ }^{522}$.

ad 2: LaCK of Physical Exercise.-Supperssion of all physical motion outlets for the phylogenetically deeply rooted fight and flight reflexes is imposed by the rules of civilized behavior. In addition, the steadily increasing perfection of labor-saving and transportation devices in industrialized nations has created an unprecedented degree of deliberate physical motionlessness.

This state of affairs is demonstrably accompanied by a deterioration of cardiac antiadrenergic counter-regulatory mechanisms, namely of the heart-decelerating vagal tone and the sympathoinhibitory hypothalamic interference in catecholamine action ${ }^{53) 54}$. In striking contrast to the vagotonic and sympatho-inhibited "athlete's heart", the "loafer's heart" of sedentary persons is characterized by a high sympathetic tone at rest ${ }^{55}$ (Fig. 6) and an exaggerated sympathetic nervous reactivity to sensory and emotional stresses ${ }^{56)}$, as manifested by an accelerated heart rate, a shortened isometric contraction period of the left ventricle, and a shortening of the relative length of the diastole 56).

A direct relationship between habitual lack 


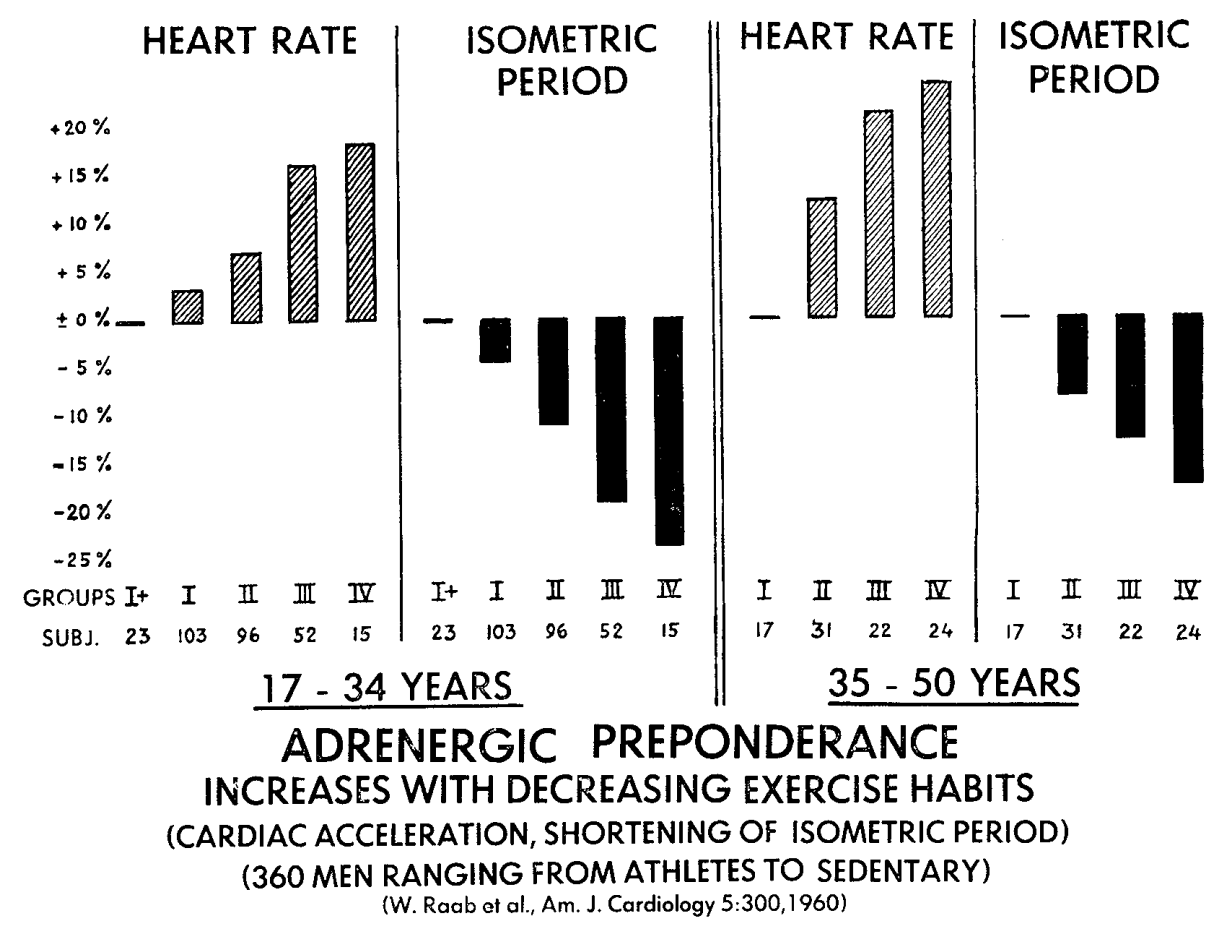

Fig. 6.

of physical exercise on the one hand, and a three- to four-fold increase of cardiac morbidity or mortality on the other has been clearly established by numerous surveys in Europe, Israel and America ${ }^{53) 57-60)}$.

ad. 3: Tовассо Smoking.- - An important contributory role of heavy smoking in cardiac mortality has likewise been statistically demonstrated $^{61>62)}$. It does not permanently elevate the sympathetic tone ${ }^{63}$ but each individual act of smoking increases myocardial oxygen consumption temporarily ${ }^{43}$ and thus creates an insidious summation of attacks on the heart muscle's integrity which become increasing critical with decreasing compensatory dilatability of the coronary arteries ${ }^{43}$.

\section{Predictability}

Objective criteria ("risk factors") which permit the prediction of ischemic heart disease with some degree of probability have been evaluated in large statistical studies ${ }^{6465}$. They consist mainly of sustained arterial hypertension, cardiac hypertrophy, hypercholesterolemia, obesity, and combinations of these. In more advanced stages, they are accompanied by electrocardiographic changes of the "hy- poxia" type.

A potential cardiac predisposition test for the early, premorbid recognition of an elevated cardiac sympathetic tone and response to standardized mild sensory and mental stresses (noise of telephone bell, flicker light, mental arithmetic) has been developed by us in recent years $^{56)}$. (Fig. 7) It showed augmented heart rates and a shortening of the isometric period and of the relative length of the diastole of the left ventricle in physically inactive and in emotionally high-strung, excitable, but otherwise still healthy individuals.

Patients suffering from angina pectoris discharge exaggerated amounts of catecholamines into the blood under physical and emotional stress $^{14>66 \sim 68)}$. These biochemical findings seem to agree with the recent observation of $\mathrm{E}$. KImURA that patients with anginal pain during exercise display a higher percentile rise of heart rate and blood pressure than those without pain ${ }^{69}$.

Thus, any early obtained objective evidence of sympathetic neurohormonal over-activity should serve as a valuable adjunct to the above-named conventional criteria of predictability. 


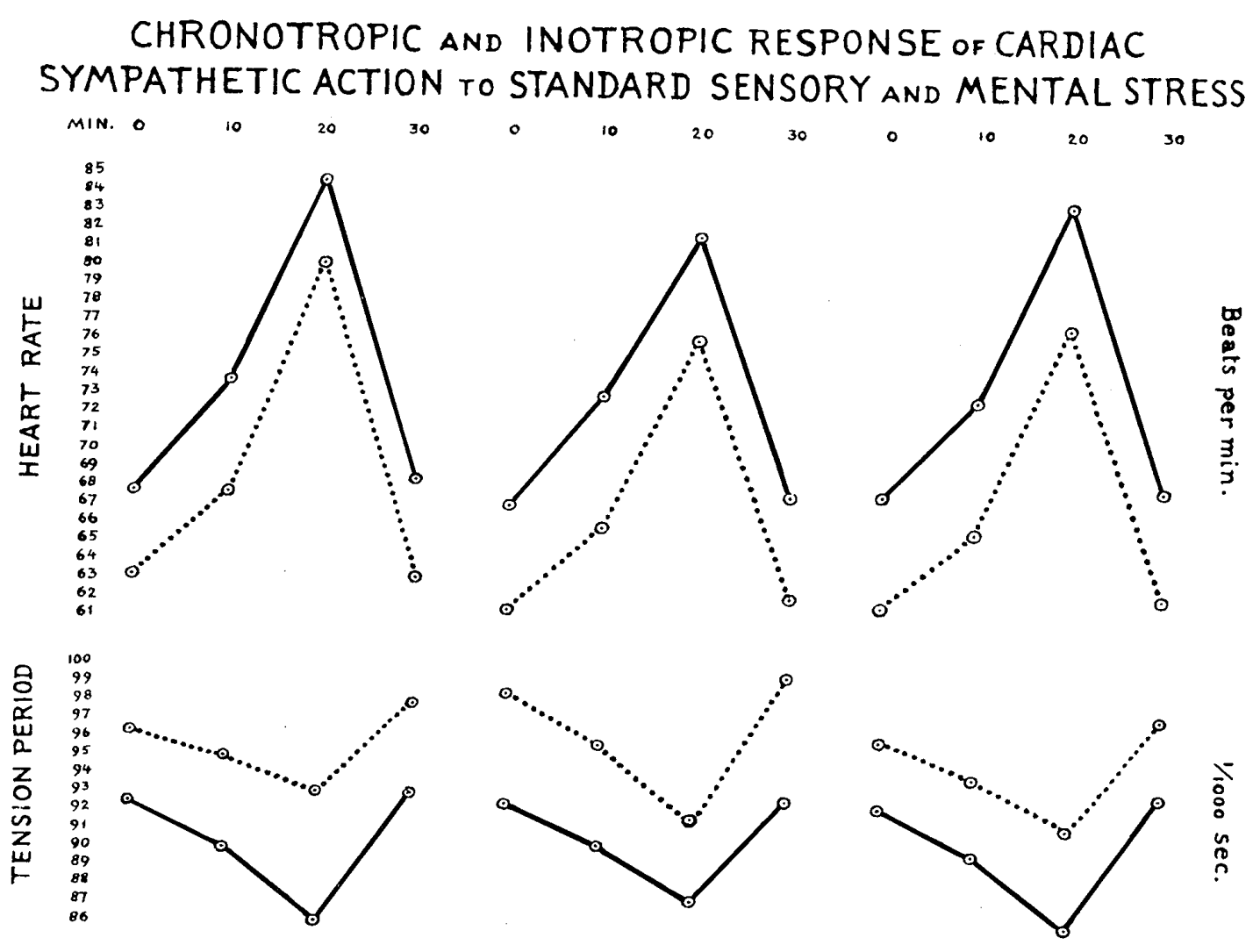

EMOTIONAL PATTERNS

- average +6.5 (49 cases)

..... AVERAGE -1.6 (28 CASES)

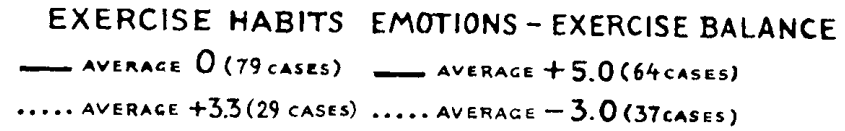

Fig. 7. The curves indicate the reactions of the heart rate and the isometric period of the left ventricle during three successive phases of the test, namely: (a) sensory stress (=telephone bell and flicker light); (b) the same continued plus mental arithmetic; (c) rest (10 minutes) each.

Subjects were grouped either according to emotional personality patterns ercise habits alone, or according to a combination of emotion and exercise score point. Solid lines denote the reactions of the emotionally most exitable or the physically most inactive subjects or those with the highest "balance" scores. Dotted lines denote the reactions of the least excitable, the physically most active and the lowest "balance" subjects.

It would seem interesting to compare the often very intensive individual, and the high average reaction of our 200 intellectual American test subjects to the sensory and mental stress test ${ }^{56)}$ with those to be observed on a comparable group of Japanese intellectuals, by applying to them the same technique.

\section{Prevention}

With the preceding discussions in mind, it is possible to approach the problem of preventing cardiac mass mortality by acting simultaneously against each one of the above identified pathogenic factors.

In the United States, some public warnings have been uttered against the excessive consumption of saturated fats in the diet, and against smoking. Otherwise, no official plan for early prevention has yet been initiated by governmental or private agencies, despite the staggering number of nearly one million cardiovascular deaths per year with a large proportion of ischemic heart disease.

Some relatively small but excellently organized programs of systematically graded physical training for middle-aged and older men have been conducted in recent years by Drs. T.K. Cureton in Urbana, Illinois, H.K. ${ }^{70)}$ HeLLERSTEIne $\mathrm{t}$ al. in Cleveland, $\mathrm{Ohio}^{71)}$, and $\mathrm{J}$. Naughton et al. in Oklahoma City, Oklahoma 
72). The two latter teams train also patients who had suffered myocardial infarctions, and they report remarkable improvements of cardiac and general fitness ${ }^{71) 72)}$.

It seems that, due to the commonly occurring fall of the diastolic blood pressure during exercising, the danger of untoward accidents in individuals with coronary sclerosis is much smaller than one might have expected. Besides, in ishemic hearts, exercise training promotes the development of a richer collateral vascular network ${ }^{73)}$. It is of interest that in contrast to the emotionally induced rise of the 17-hydroxycorticoteroid level in the blood ${ }^{38) 40)}$, T. SUzUKI ${ }^{74}$ has found the amount of these corticoids nearly unchanged in the blood of the adrenal veins during exercise of a nonexhausting degree. Hence, the highly cardiotoxic combination of corticoid and catecholamine action $^{38)}$ may be avoidable by graded, moderately strenuous physical training.

The communist countries of Eastern Europe, notably the Soviet Union, but more recently also West Germany, Austria and Switzerland, have established nearly 3,000 preventive Reconditioning Centers in beautiful, climatically favorably located mountainous areas (Caucasus, Alps, etc.), for yearly approximately 5 million fatigued, tense and exhausted, but not necessarily overtly sick workers, employees and executives $^{7576)}$.

The programs in these government-, industry-, and insurance-sponsored centers, even though developed merely on an empirical basis, are essentially aimed at counteracting the above-discussed detrimental adrenergic features of modern, civilized living. They offer during periods of at least four weeks per trainee environmental-emotional relaxation, combined with medically supervised, individually adjusted vigorous physical out-door activities, such as hiking, mountain climbing, calisthenics, breathing exercises and water applications, plus a thorough indoctrination of life-long health rules, including non-smoking and dieting.

Exercise breaks, like those practiced in somé Japanese industrial plants, are also customary in Eastern European countries.

Long-range morbidity and mortality statistics, related to the European reconditioning systems, have not yet been published but are being collected in West Germany. The Soviet Union claims to have the lowest cardiac mortality among all civilized nations ${ }^{77)}$.

In agreement with the cardiac antiadrenergic effectiveness of physical training ${ }^{5578 \sim 80}$ and emotional relaxation ${ }^{47)}$, recent reports from West German and Austrian reconditioning centers give uniformly evidence of a reduction of the heart rate and a prolongation of the isometric period at rest, as well as a lessened cardiac acceleration during exercise. These findings indicate a lowering of cardiac sympathetic tone and reactivity as an objective beneficial result from reconditioning periods ${ }^{81-84)}$, suggesting their potential prophylactic value.

\section{SUMMARY}

Extensive investigations over the last 20 years have made it clear that the origin of ischemic heart disease (angina pectoris, ischemic myocardial necroses and fibroses, congestive heart failure) cannot be attributed to coronary vascular lesions alone.

Augmentations of myocardial oxygen consumption under the dominating influence of the adreno-sympathogenic catecholamines, norepinephrine and epinephrine, contribute fundamentally to the metabolic vulnerability of the heart muscle. Discrepancies between limitations of compensatory coronary oxygen supply and catecholamine-induced incrcases of myocardial oxygen consumption lead to local anoxia and structural damage, especially in the vascularly handicapped left ventricular subendocardium.

Over-civilized, prosperous, competitive, and sedentary living causes a detrimental sympathetic adrenergic preponderance in myocardial metabolism, both by emotional direct sympathetic stimulation and by a deterioration of antiadrenergic (vagal and sympathoinhibitory) counter-regulation, which results from lack of physical exercise. Nicotine contributes further to harmful catecholamine discharges. Emotioninduced overproduction of adrenal 17-hydroxycorticoids may provide an additional aggravating factor.

Objective criteria for the early recognition Japanese Circulation Journal Vol. 29, February 1965 
of cardiac ischemia-proneness, and preventive measures to avoid coronary atherosclerosis as well as neurogenic myocardial metabolic vulnerability are briefly discussed.

The striking contrast between the incidence of ischemic heart disease in Japan and some Western countries deserves a systematic investigation concerning possibly co-responsible neurogenic and hormonal, emotional and physical activity factors beside the well-known dietary differences.

\section{REFERENCES}

1) Raab, W.: American Heart Journal 66: 685, 1963.

2) Schimert, G. et al.: Handbuch d. inn. Med., vol. 9/III, Springer, Berlin, 1960 (pp. 725-731; 847-867; 884-888; 911-917; 974-989; 1494-1505).

3) Myasnikov, A.L. : American Journal of Cardiology 13: 435, 1964.

4) Seki, A.: Fukuoka acta medica $50: 2252,1959$

5) Gore, J., Nakashima, T. and White, P.D.: Procedings New England Cardiovascular Society, Jan. 9, 1961, Page 17.

6) Kimura, N. : Cardiologia pratica $13: 200,1962$.

7) Tamari, K. : Igaku Kenkyuu 32: 23, 1962.

8) Okinaka, S. et al. (Committee Report). Japanese Circulation Journal 21: 1, 1957.

9) Keys, A.: Journal of American Med. Assoc., 164 : 1912, 1957.

10) Blumgart, H.L., Schlesinger, M.J. and Zoll, P. M. : Journal of American Medical Association 116: 91, 1941.

11) Ehrlich, J.C. and Shinohara, Y.: Circulation 26 : 710, 1962.

12) Bücher, F.: Dtsch. med.Wschr. 82: 1037, 1957.

13) Raab, W. : Revu e. Canadienne de Biologie 22: 217, 1963.

14) Kaab, W.: Hormonal and Neurogenic Cardiovascular Disorders, Williams \& Wilkins, Baltimore, 1953.

15) Melville, I.K. and Share, N.N. : Revu e. Canadienne de Biologie 22 : 265, 1963.

16) Shkhvatsabaya, Y.K. and Menshikov, V.V. : Kardiologiya (Moscow) 2: no. 6, 27, 1962.

17) Miminoshvili, D.J., Magakyan, G.O. and Kokaya, G. Ya.: Voprosy fiziologii y patologii obyezyan, Sukhumi. 1961.

18) Groover, M.E. : Circulation 26: 645, 1962.

19) Raab, W., Chaplin, J.P. and Bajusz, E.: Proceedings of Society of Experimental Biology and Medicine, 116: 665,1964

20) Wenzel, D.G. : Proceedings of First International Conference on Preventive Cardiology, Burlington, Vermont, Queen City Printers, 1964, p. 15. Abstract No. 10.

21) Raab, W. and Gigee, W.: Circulation Research 3 : $553,1955$.

22) Raab, W. Stark, E., Macmillan, W.H. and Gigee, W. : American Journal of Cardiology 8: 203, 1961.

23) Bajusz, E., Selye, H. and Strebel, R. : III. World
Congress of Psychiatry, Montreal, June 1961.

24) Nakabayashi, Y.: Igaku Kenkyuu 23 : 14, 1935.

25) Ueba, Y.: Unpublished data.

26) Prinzmetal, M., Bergman, H.C., Kruger, H.E., Schwartz, L.L., Simpkin, B. and Sobin, S.S.: American Heart Journal 35 : 689, 1948.

27) Okinaka, S., Ikeda, M., Hashiba, K., Murata, K., Kaneko, J., Ozawa, T., Niitani, H., Ishimi, Z., Fujii, J., Takeda, Y., Kuramoto, K., Tsubjii, M. and Terasawa, F.: American Heart Journal 56:319, 1958.

28) Schütz, E. : Zeitschrift für Kreislaufforschung $\mathbf{4 5}$ : $708,1956$.

29) Salisbury, P.F., Cross, C.E. and Riebens, P.A. : American Heart Journal 66 : 650, 1963.

30) Lepeschkin, E.: Modern Electrocardiography, Williams \& Wilkins, Baltimore, Maryland, 1951.

31) Sayen, J.J., Katcher, A.H., Sheldon, W.F. and Gilbert, C.M. : Circulation Research 8 : 109, 1960.

32) Bretschneider, H.J., Frank, A., Kanzow, E. and Bernard, U. : Deutsche Gesellschaft für Kreislaufforschung 22: $300,1956$.

33) Bajusz, E. and Raab, W.: First International Conference on Preventive Cardiology, Queen City Printers, Burlington, Vermont, 1964, page 11, abstract No. 3.

34) Shimamoto, T. and Hiramoto, Y, : Unpublished data.

35) Mölbert, E.: Beitr. z. path. Anat. u. z. allg. Pathol. 18: 421, 1957.

36) Caulfield, J. and Klionsky, B. : Am. J. of Pathology 35 : 489, 1959.

37) Bryant, B.E., Thomas, W.A. and $\mathrm{O}^{\prime}$ Neal, R.M. : Circuiation Research 6: 699, 1958.

38) Selye, H.: The Pluricausal Cardiopathies. C.C Thomas, Springfield, Illinois, 1961.

39) Pekkarinen, A., Tala, E., Sotaniemi, E. and Niemelä, N. : Biochem. Pharmaciol. 8, No. 1, August 1961.

40) Mason, J.W., Mangan, G., Brady, J.B., Conrad, D. and Rioch, D. McK.: Psychosomatic Medicine 23: 344, 1961.

41) Kimura, E., Suzuki, N., Kanazawa, T., Ito, Y., Harigai, N., Yamamoto, F., Kumagai, S., Suzuki, Y. and Obara, F.: Tohoku Journal Experimental Medicine 66: 25, 1957.

42) Raab, W., van Lith, P., Lepeschkin, E. and Herrlich, H.C. : American Journal of Cardiology 9: 455, 1962.

43) Bellet, S., West, J.W., Manzoli, U.C., Muller, O.F. and Rossi, p.: Annals New York Academy of Medical Sciences, 90: 317, 1960.

44) Satake, Y.: Tohoku Journal of Experimental Medicine, supplement, $\mathbf{6 0}: 2,1954$.

45) Tomomatsu, T., Ueba, Y., Matsumoto, T., Ikoma, T. and Kondo, Y.: Japanese Heart Journal 4: 13, 1963.

46) Chidsey, C.A., Harrison, D.C. \& Braunwald, E. : New England Journal of Medicine 267: 650, 1962.

47) Levi, L.: Acta psychotherapeutica 11 : 218, 1963.

48) Friedman, M., St. George, S., Byers, S.O. \& Rosenman, R.H.: Journal of Clinical Investigation 39: $758,1960$.

49) Rosenman, R.H., Friedman, M., Straus, R., Wurm, M., Kositcheck, R. Hahn, W. and Werthessen, N.: 
Journal of the American Medical Association 189: $15,1964$.

50) Russek, H.I. : American Journal of Medical Sciences 240: 79/711, 1960.

51) Wolf, S. : First International Conference on Preventive Cardiology, Queen City Printers, Burilingtan, Vermont, Page 24, abstract no. 24, 1964.

52) Lapiccirella, V., Lapiccirella, R., Abboni, F. and Liotta, S.: Bulletin World Health Organization 27 : 681, 1962.

53) Kraus, H. and Raab, W.: Hypokinetic DiseaseDiseases Produced by Lack of Exercise. C. C Thomas, Springfield, Illinois, 1961.

54) Folkow, B., Johansson, B. and Oeberg, B. : Acta physiologica scandinavica 47: 262, 1959.

55) Raad, W., de Paula e Silva, P., Marchet, H., Kimura, E. and Starcheska, Y.K.: American Journal of Cardiology 5 : 300, 1960.

56) Raab, W. and Krzywanek, H.J.: American Journal of Cardiology (in press)

57) Morris, J.N., Heady, J.A., Raffle, P.A.B., Roberts, C.G. and Parks, J.W.: Lancet 2: 1053, and 1111, 1953.

58) Brunner, D. and Manelis, G. : Lancet 2 : $1049,1960$.

59) Myasnikov, A.L. : Cardiologia pratica 13: 72, 1962.

60) Hames, C.G. : First International Conference on Preventive Cardiology, Queen City Printers, Burlington, Vermont, 1964 (supplement, page 2).

61) Hammond, E.C. and Horn, D.: Journal of the American Medical Association 155 : 1316, 1954.

62) Doyle, J.T., Dawber, T.R,. Kannel, W.B., Heslin, A.S. and Kahn, H.A.: New England Journal of Medicine 266 : 796, 1962.

63) Raab, W., Marchet, H. and Deming, H.: Experimental Medicine and Surgery 18: 128, 1960.

64) Kannel, W.B., Dawber, T.R., Kagan, A,. Revotrkie, N. and Stokes, J.: Annals of Internal Medicine 55: 33, 1961.
65) Hall, O., Lepper, M.H., Ostfeld, A., MacMillan, A. and Phelan, W.H. : Circulation 26: 770, 1962.

66) Gazes, P.C., Richardson, J. and Woods, E.F. : Circulation 19: 657, 1959.

67 Starcich, R. and Ambanelli, U. : Giornale di Clinica Medica 40: 1, 1959.

68) Starcich, R.: Acta III. Europaei de cordis scientia conventus Excerpta Medica, Roma, 1960, page 155.

69) Kimura, E. : Unpulished data.

70) Cureton, T.K. : Journal Association for Physical and Mental Rehabilitation 10: 3, 75, 1956.

71) Hellerstein, H.K. : First International Conference on Preventive Cardiology, Queen City Printers, Burlingtion, Vermont, 1964, page 29, abstract no. 36.

72) Naughton, J. : First Internasional Conference on Preventive Cardiology, Queen City Printers, Burlington, Vermont, 1964, page 30, abstract no. 37.

73) Eckstein, R.W.: Circalation Research 5: 230, 1957.

74) Suzuki, T.: Unpublished data.

75) Raab, W.: Public Health Reports 78 : 371, 1963.

76) Hellerstein, H.K. : Modern Medicine, May 11, 1964, page 266.

77) Kurashov, S.V.: Organization of fight against cardiovascular diseases, Moscow, 1960.

78) Mellerowicz, H.: Archiv für Kreislaufforschung 24 : 70, 1956.

79) Reindell, H., König, K., Rosskamp, H. and Keul, J. : Die aerztliche Fortbilbung 9: 2, 1959.

80) Brouha, L.: In "Work and the Heart", Paul B. Hoeber, Inc., New York, 1959, page 180.

81) Kirchhoff, H.W. : First International Conference on Preventive Cardiology, Queen City Printer, Burlington, Vermont, 1964, page 33, abstract no. 41.

82) Blohmke, M. : ibidem, page 33, abstract no. 42.

83) Marchet, H. : ibidem, page 34, abstract no. 43.

84) Schmidt-Kessen, W., Groh, W. and Gross, W.: Arch. phys. Ther. 15: 325, 1963. 